\title{
Coaliciones y traiciones masónicas. De la primera reelección de Porfirio Díaz a los inicios de la revolución mexicana, 1887-1911
}

\begin{abstract}
Carlos Francisco Martínez Moreno
Maestro en Historia por la Facultad de Filosofía y Letras de la Universidad Nacional Autónoma de México, UNAM y catedrático de "Historia de la Masonería en México" en la misma institución. Correo electrónico: maqui030507@yahoo.com
\end{abstract}

DOI: http://dx.doi.org/10.15517/rehmlac.v7i2.22853

Fecha de recibido: 12 de septiembre de 2015 - Fecha de aceptación: 5 de octubre de 2015

Palabras claves

Rito Escocés, Supremo Consejo de México, Gran Dieta, Gran Logia Valle de México, Revolución

Keywords

Scottish Rite, Supreme Council of Mexico, Grand Diet, Grand Lodge Valley of Mexico, Revolution

\section{Resumen}

En México desde la primera reelección en la presidencia del general Porfirio Díaz en 1887 hasta su salida en 1911 en los inicios de la revolución mexicana varios grupos disputaron por el poder político, en esta investigación se busca mostrar que durante ese período diferentes procesos electorales, movimientos sociales y revolucionarios fueron el resultado de coaliciones y de traiciones masónicas.

\begin{abstract}
In Mexico, between the first re-election in the presidency of General Porfirio Diaz in 1887 until his departure in 1911 at the beginning of the Mexican Revolution, various groups competed for political power This research seeks to show that during this period, different electoral processes, social movements and revolutionaries came about as the result of coalitions and freemasonic betrayals.
\end{abstract}

\section{Introducción}

En México de mediados del siglo XIX a inicios del XX varios bandos políticos pugnaron por la presidencia de la república, en esta investigación se tratará de mostrar que fueron grupos masónicos que influyeron desde la primera reelección de Porfirio Díaz en 1887 hasta los inicios de la revolución mexicana en el año de su salida del país en 1911.

Las fuentes permitieron identificar las posturas políticas antagónicas que adoptaron los masones: apoyaron a Porfirio Díaz, lo combatieron para buscar la transición electoral o la revolución política, liberal, social por vía violenta o la paz, pactaron con el clero católico, trabajaron por la redimir al pueblo e incluso favorecieron la intervención de Estados Unidos. 
Entre las limitantes del estudio de los grupos masónicos se encuentra el reporte parcial de listados, que incluyen sólo a quienes ocuparon altos cargos, por lo que las menciones sobre la pertenencia de políticos a la masonería sin apoyo documental fueron descartadas, sólo se consideraron las confirmados en listas oficiales. Otro problema resultó de no contar con información para todos los años. Dicho lo anterior, abordemos el tema.

\section{Imagen 1}

General José de la Cruz Porfirio Díaz Mori (Oaxaca México, septiembre 15, 1830-París, Francia, julio 2,1915$)$ porta el collarín y la joya del grado $33^{\circ}$, en su calidad de Soberano Gran Comendador ad vitam del Supremo Consejo de México

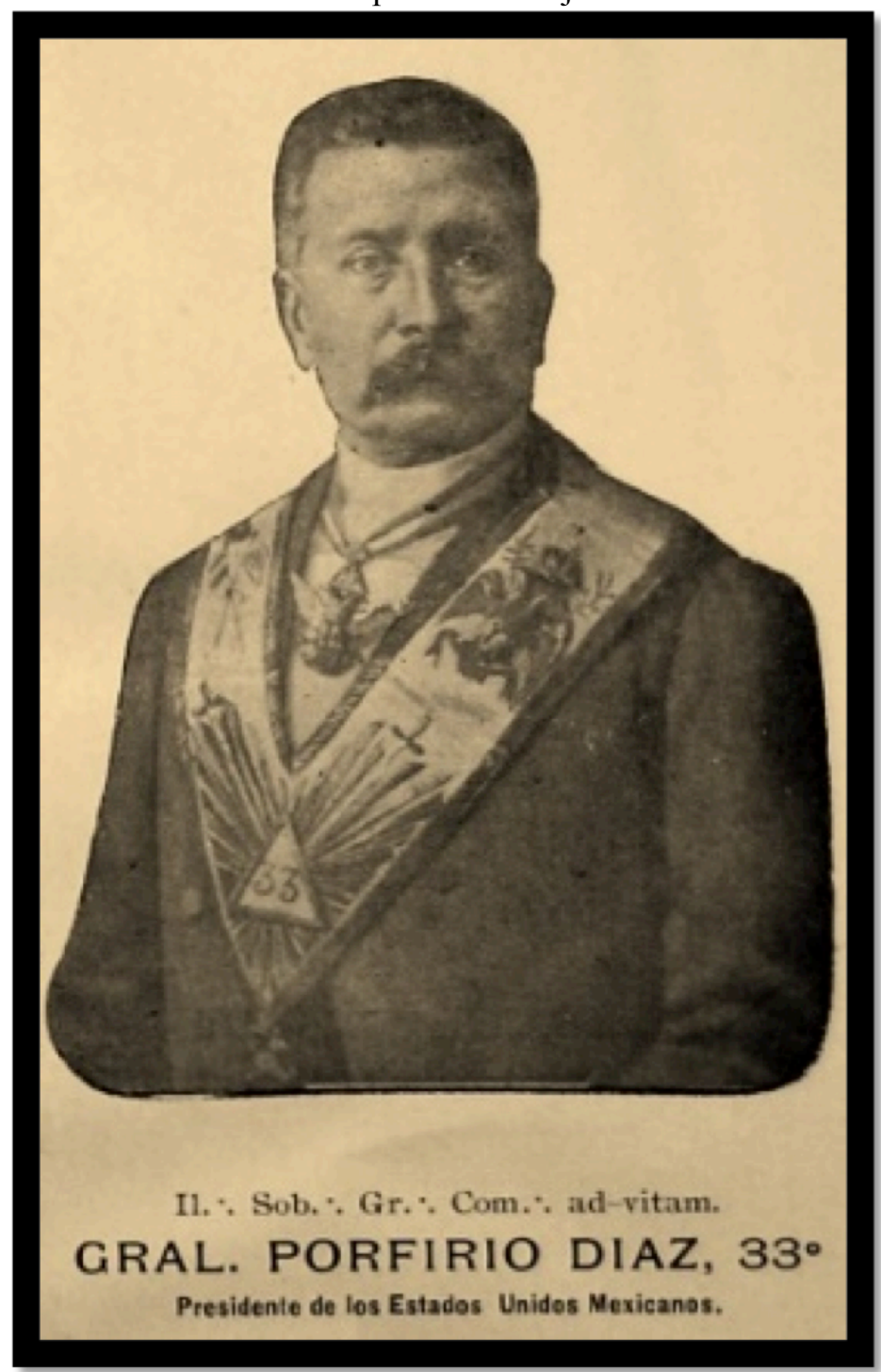

Fuente: Supremo Consejo del 33 y último grado del Rito Escocés Antiguo y Aceptado para la jurisdicción masónica de los Estados Unidos Mexicanos, Boletín Anual del Supremo Consejo del Rito Escocés Antiguo y Aceptado para los Estados Unidos Mexicanos (México: Litografía e Imp. 'El Monograma', Año $1^{\circ}$ del $8^{\circ}$ quinquenio, del 28 de Abril de 1898 al 28 de Abril de 1899), hoja aparte sin número entre las páginas 16 y 17. 


\section{La coalición masónica y la primera reelección}

Desde 1887, algunos masones diputados impulsaron en el Congreso la re-elección de Porfirio Díaz, como los escoceses Juan N. Castellanos, Joaquín Diego Casasús, Francisco Romero y Sóstenes Rocha, los tres últimos eran miembros del Gran Oriente de Ignacio Manuel Altamirano y, después, todos serían integrantes de la Gran Dieta Simbólica de los Estados Unidos Mexicanos que encabezó Díaz.

La Dieta fue creada para unir la masonería nacional, varias corrientes reñían desde 1878, desde que el Supremo Consejo escocés de Alfredo Chavero (grados $1^{\circ}-33^{\circ}$ ) le negó la libertad del simbolismo (grados $1^{\circ}-3^{\circ}$ ) a Ignacio Manuel Altamirano el gran maestro de la Gran Logia Valle de México; quien por ello separó su obediencia y, tras su salida, el Supremo Consejo creó otra que llamó del Distrito Federal dirigida por Carlos Koch Ruiz, a quien apoyaron los escoceses de México y Albert Pike, líder mundial de ese rito, quien desde Estados Unidos le creó la fama como grupo regular.

Porfirio Díaz en 1877 había proclamado el Plan de Tuxtepec contra la reelección del masón del Rito Nacional Mexicano Sebastián Lerdo de Tejada ${ }^{1}$; y junto con otros de ese rito que militaban a su vez en el escocés, empoderaron a Alfredo Chavero como comendador del Supremo Consejo, y a partir de 1878 acaeció una contienda con dos bandos, los chaveristas o consejistas y los altamiranistas que en 1883 crearon el Gran Oriente.

Años después, el comendador de entonces del Supremo Consejo Ignacio Pombo, el 2 de enero de 1890 divulgó el tratado por el que el día 15 siguiente disolverían el Gran Oriente para crear la Dieta ${ }^{2}$ con el aval de Pike, a quien Pombo dijo el 13 de febrero que con ello seguía "sus sabios consejos" "para terminar el cisma" que los dividió más de 13 años y consideraba como recompensa su aprobación ${ }^{3}$. La unificación la operaron los generales Carlos Pacheco y Ramón Corona, éste último murió asesinado antes a finales de 1889 y no concluyó su misión, en su lugar la operaría el general Sóstenes Rocha; a Altamirano, Porfirio Díaz dio una salida diplomática al enviarlo en comisión a España.

Ambos grupos para 1889 habían dividido el país, en tanto que los adeptos de Carlos K. Ruiz crearon grandes logias montados en la regularidad que le consiguió Pike. Lo grave de la división fue que entre 1888 y 1889 impactó entre los gobernadores, y puesto que casi todos eran militares había riesgo de un enfrentamiento armado, véase el mapa 1.

\footnotetext{
${ }^{1}$ Carlos Francisco Martínez Moreno, "Masonerías y construcción de una geopolítica nacional”, en Escenarios geopolíticos para el México global. Un acercamiento a los temas del siglo XXI, coord. por Arturo Ponce Urquiza (México: Centro de Estudios Superiores Navales CESNAV/Grupo Editorial Cenzontle, 2015), 154155, Anexo A, 165.

${ }^{2}$ El Boletín Masónico. Órgano Oficial del Sup[remo] Gr[an] Or[iente] de los Estados Unidos Mexicanos, Revista de la Masonería Universal (México: T. X, A. X., 1889, octubre-diciembre, Nos. 10-12, 509-511). Ignacio Pombo, Balaustre 35, Tercera Serie, México, 25 del $3^{\text {er }}$ mes masónico Kislev de 5650, enero 2, 1890.

${ }^{3}$ Pombo, Carta a Alberto Pike en Washington D. C., México, febrero 13, 1890.
} 
Mapa 1

Distribución geopolítica de masones gobernadores de Estado, 1888-1889

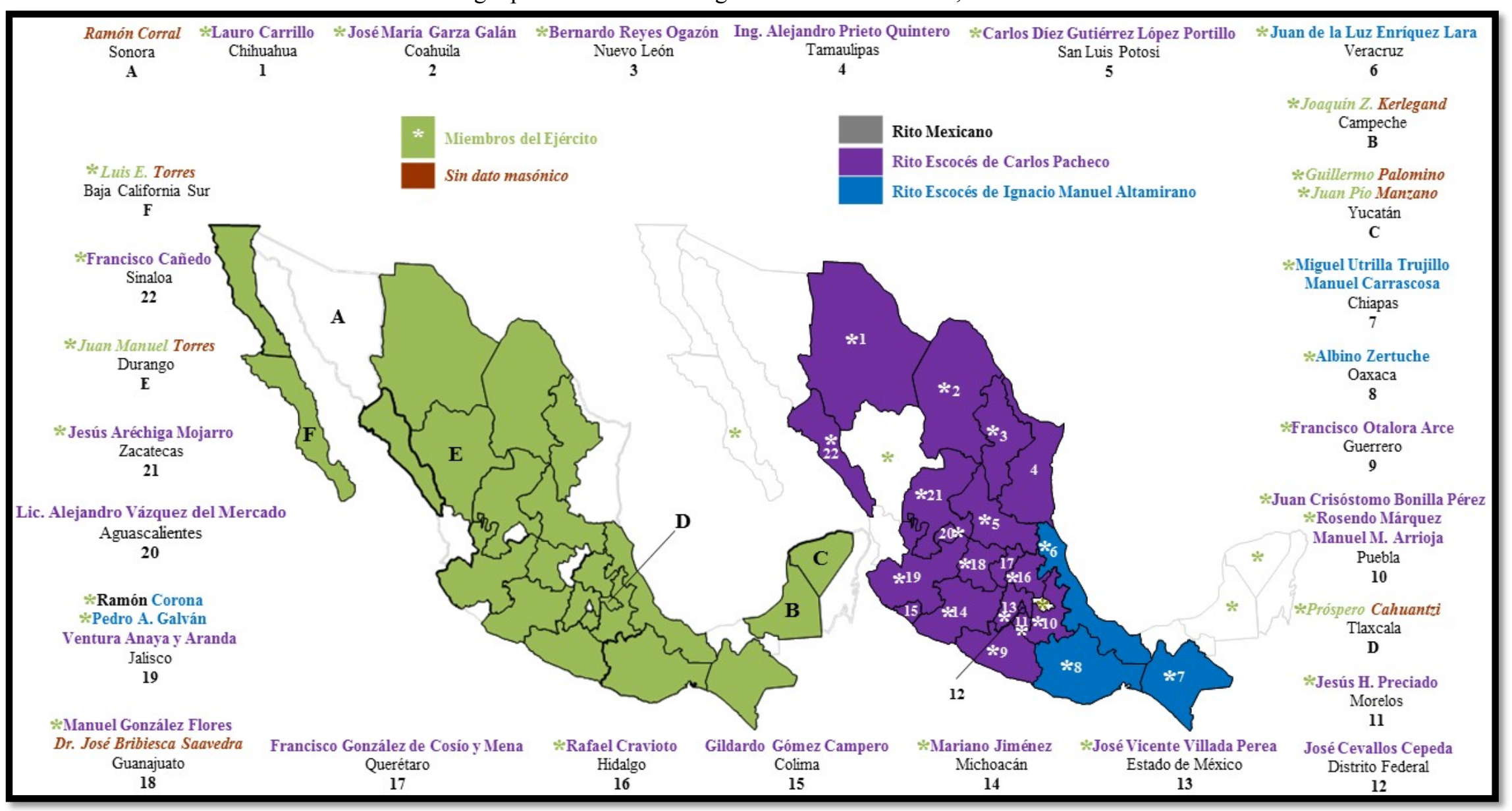

Elaboración propia

Fuentes: El Boletín Masónico, Órgano Oficial del Supremo Gran Oriente de los Estados Unidos Mexicanos, Revista de la Masonería Universal (México: 1888-1889). Boletín Anual del Supremo Consejo del Rito Escocés Antiguo y Aceptado para los Estados Unidos Mexicanos (México: 1888-1889). Felipe B. Berriozabal, Memoria que el Secretario de Estado y del Despacho de Guerra y Marina Gral. De División Felipe B. Berriozabal presenta al Congreso de la Unión y comprende de 19 de marzo de 1896 a 30 de junio de 1899, (México: Imprenta 'Central', Anexos, Tomo II, 1900). 
En apoyo al presidente Díaz, en 1892 masones crearon la liga política LA UNIÓN LIBERAL, en su mayor parte escoceses: general Ignacio R. Alatorre, Francisco de P. Gochicoa (rito mexicano), Juan Dublán, Eduardo Dublán, Juan de Dios Peza, Francisco Mejía, Carlos Díaz Dufóo, Carlos Quaglia, Rafael Dávila, Ismael C. Zúñiga y Enrique Valle. Asimismo, masones formaron el PARTIDO LIBERAL MEXICANO de la República: Joaquín D. Casasús, Mariano Escobedo (mexicano-escocés), Benito Juárez Maza (rito mexicano), Ignacio Pombo, Carlos Quaglia y Sóstenes Rocha ${ }^{4}$.

En 1893 la Dieta tenía 17 obediencias en 16 entidades: Ciudad de México GRAN LOGIA VALLE DE MÉXICO 1, Toluca Estado de México DE LIBRES Y ACEPTADOS MASONES 2 después aparece como MIGUEL HIDALGO 2, Jalapa Veracruz EL SOL 3, Jalisco ESTADO DE JALISCO 4 luego BENITO JUÁREZ DEL ESTADO DE JALISCO 4, Piedras Negras Coahuila BENITO JUÁREZ 5, Zacatecas UNIÓN PERPETUA 6, Monterrey Nuevo León UNIÓN 7, San Cristóbal de la Casas Chiapas EL FARO 8, Tamaulipas en Tampico IGNACIO RAMÍREZ 9 y en Nuevo Laredo LUZ DE LA FRONTERA 14, Oaxaca VÍCTOR HUGO 10, Guerrero VICENTE GUERRERO 11 después aparece como Villa de Lerdo Durango DEL ESTADO DE DURANGO 11, Aguascalientes DE ESTADO "REGENERACIÓN" 12, Paso del Norte Chihuahua COSMOS 13, Puebla DE LIBRES Y ACEPTADOS MASONES 15, San Luis Potosí DE ESTADO EL POTOSÍ 16, Tabasco DEL ESTADO DE TABASCO 17. Así, entre 1890 y 1895 la Dieta fue construyendo una red de gobernadores, con 13 de ellos como delegados, superando las divisiones entre los escoceses, véase el mapa 2.

\footnotetext{
${ }^{4}$ El Siglo Diez y Nueve. Decano de la Prensa Mexicana, México, 1892, 9 a Época, A. 51, T. 101, N. 16, 219, enero 29, 1-2; N. 16,243, febrero 26, 2. La Convención Radical Obrera. Órgano de la Sociedad del mismo nombre y de las clases obreras de toda la República, México, 1892, A. VI, N. 374, febrero 28, 1.
} 
Mapa 2

Distribución geopolítica de masones gobernadores de Estado, 1890-1895

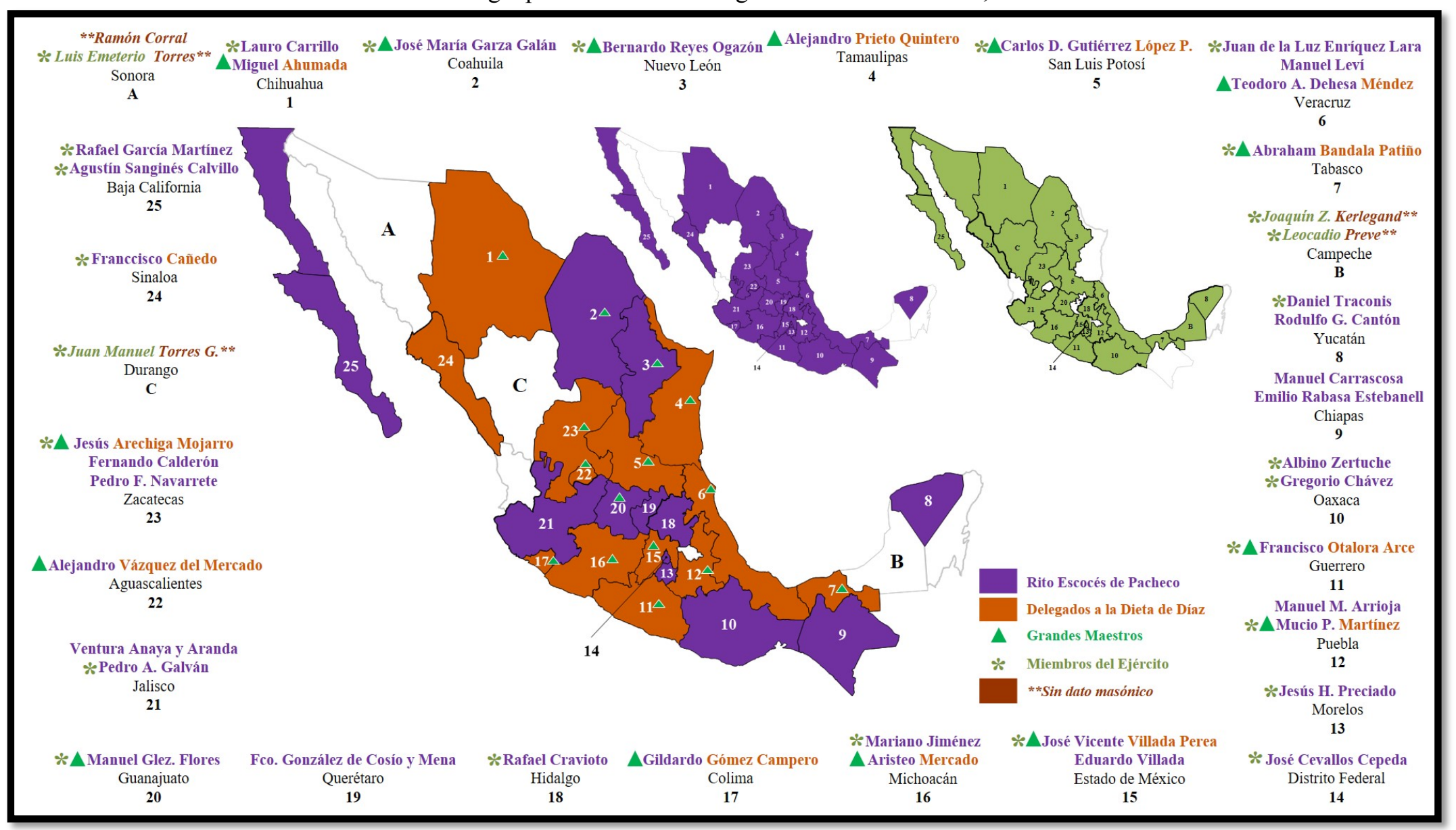

Elaboración propia

Fuentes: Boletín Masónico, Órgano Oficial de la Gran Dieta Simbólica de los Estados Unidos Mexicanos (México: 1890-1895). Boletín Anual del Supremo Consejo del Rito Escocés (México: 1890-1895). Berriozabal, Memoria. 


\section{Causas del cisma}

Desde 1893, Richard Chism de la logia extranjera Toltec 520, creada en la ciudad de México bajo la Gran Logia de Missouri por el coronel J. W. DeGress, envió a ésta el 31 de marzo el panfleto An Inside View of Mexican Masonry para acusar a la Dieta de aceptar mujeres y de no usar la biblia. Freke Gould copió las denuncias en la revista Ars Quatuor Coronati con el título Freemasonry in Mexico ${ }^{5}$.

La Dieta afirmaba apegarse a las Constituciones de 1721-1723, lo que sí cumplía en parte, porque la exigencia del uso de la biblia en la masonería fue una innovación posterior en torno a 1760, así que esa acusación no se sostenía, pero como la regularidad consistía en hacer lo que las grandes logias que se decían regulares prescribían, su criterio se impuso. Respecto a que incluyó a la mujer, es cierto. La masonería de la Dieta, a diferencia de la original del siglo XVIII, reconoció la igualdad de género y a la mujer su derecho a votar y a ser votada, y tuvo entre sus dirigentes mujeres intelectuales, profesionistas y emancipadoras, pero pronto desde el extranjero se le obligó a mutilar ese proyecto ${ }^{6}$.

También se culpó a los masones de la Dieta de participar en política, era verdad, pero la delación esconde que sus acusadores no estaban exentos de lo mismo; incluso desde la creación de la Gran Logia de Londres, el duque de Wharton, bajo cuyo período fueron establecidas las constituciones de 1723, hizo política para traicionar a su Rey Jorge I, fundó un periódico contra él, apoyó al partido de los Tories y fundó un grupo antimasónico, y la presunta apolítica masónica la usó para encubrir a los jacobinos que se valieron de la tolerancia religiosa como ideología contra el reino inglés para practicar el culto del monarca extranjero de los estados pontificios contra las disposiciones de su monarca ${ }^{7}$.

La Dieta enfrentó las acusaciones con su Boletín y contestó que eran falsas; pero sí eran verídicas aunque algunas infundadas como ha sido explicado, sólo que los acusados lo ignoraban y para 1895 se unieron a la protesta en contra suya las logias de extranjeros Anáhuac, Toltec y Germania y finalmente lograron que fuera desconocida por las obediencias de Inglaterra y de Estados Unidos, con ello la obligaron a desterrar la masonería femenina y hacer obligatorio el uso de la biblia y, al final de agosto, a que renunciaran a sus cargos en ella el presidente de la república y gran maestro Porfirio Díaz,

\footnotetext{
${ }^{5}$ Robert Freke Gould, Freemasonry in Mexico (U. S. A.: Kessinger Publishing, reprinted from Keble's Gazette Office, 1893 and from "Ars Quatuor Coronati", London, reprinted by Kessinger Publishing, s.a.).

${ }^{6}$ Martínez Moreno, "Auge y Caída de la Masonería en México en el Siglo XIX. La Exclusión de la Mujer bajo la mirada del Discurso Masónico de Laureana Wright González", REHMLAC 4, no. 2, (diciembre 2012abril 2013): 129-155 [citado el 21 de octubre de 2015]: disponible en http://revistas.ucr.ac.cr/index.php/rehmlac/article/view/12188/11471

${ }^{7}$ José Antonio Ferrer Benimeli, La Masonería Española en el Siglo XVIII (Madrid: Siglo XXI Editores, Historia, segunda edición corregida, 1986), 53ss.
} 
y el secretario de relaciones exteriores Ignacio Mariscal ${ }^{8}$; éstas dimisiones rompieron la cadena de unión entre los masones gobernadores de estado y motivaron la separación de las grandes logias de la Dieta, por ello, para 1896 sólo le restaban 4 obediencias y ninguna de ellas dirigida por algún gobernador, en: Ciudad de México GRAN LOGIA VALLE DE MÉXICO 1, Jalisco BENITO JUÁREZ 4, Coahuila BENITO JUÁREZ 5, Tamaulipas IGNACIO RAMÍREZ 9, véase el mapa 3.

\footnotetext{
${ }^{8}$ Theodore Sutton Parvin, Mexican Masonry (Iowa: Cedar Rapids, May $17^{\text {th }}$, 1897). Richard E. Chism, Una contribución a la Historia Masónica de México (México: Imp. de El Minero Mexicano, 1899), 127. Martínez Moreno, “Auge y Caída de la Masonería en México en el Siglo XIX”, 129-155.
} 
Mapa 3

Grandes Logias bajo la juridcción de la Gran Dieta Simbólica de los Estados Unidos Mexicanos, 1890-1893 Vs. 1896

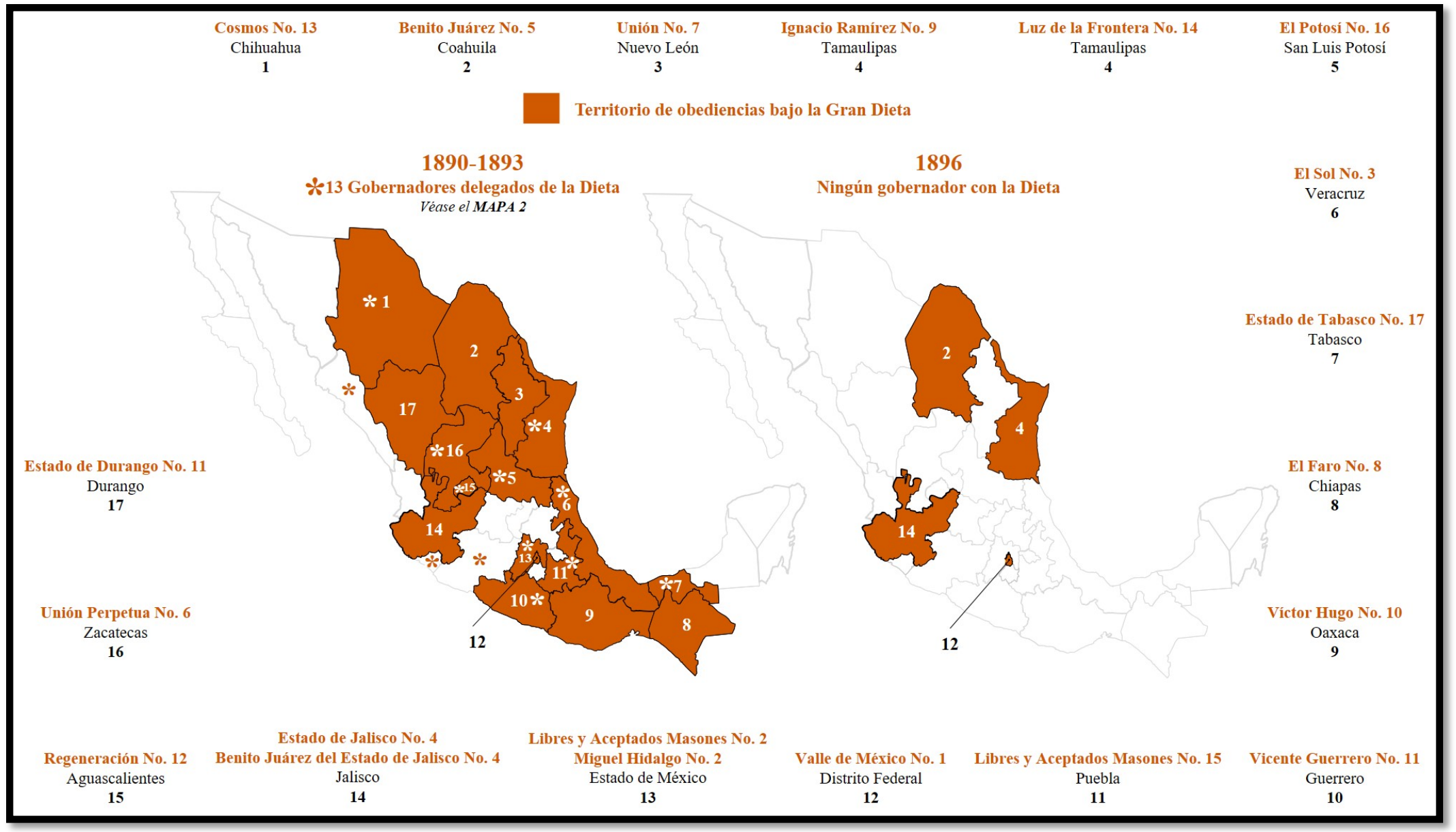

Elaboración propia.

Fuentes: Boletín Masónico, Órgano Oficial de la Gran Dieta Simbólica (México: 1890-1896). 


\section{Renuncia de Díaz}

El cisma puso a Porfirio Díaz en un dilema, o se apegaba a la exigencia de las obediencias extranjeras y frenaba la secularización masónica y excluía a la mujer, o afectaba la imagen de su gobierno al dirigir un grupo declarado irregular; optó por una salida diplomática, el 31 de agosto de 1895 dijo que quería corresponder con dedicación al cargo de gran maestre pero sus ocupaciones profanas se lo impedían, por lo que obligado renunció, suplicando contaran siempre con su adhesión a "nuestra Orden"”.

Para disminuir el daño, la Dieta divulgó que Díaz no renunció a ella sino a su cargo; y no obstante que Toltec 214 ya trabajaba bajo la Dieta desde el 4 de febrero de 1894 y que su jefe el doctor A. W. Parsons expulsó a Richard E. Chism, éste siguió acusando a la Dieta con tres obras en inglés en 1897 y otra en español en 1899, con lo que continuó el quebranto de la masonería nacionalista, secularizadora, progresista e incluyente ${ }^{10}$.

\section{El trasfondo}

El comendador escocés entre 1898 y 1907, el general Jesús Alonso Flores, magistrado de la suprema corte de justicia militar, el 7 de enero de 1900, por un conflicto con la Gran Dieta, el 12 de marzo prohibió aceptar a sus miembros y expulsó a varios, entre ellos a: Manuel Levi $33^{\circ}$, W. J. DeGress $33^{\circ}$, F. E. Young $32^{\circ}$, F. L. Austin $32^{\circ}$ y E. Dahlhaus $18^{\circ}$, a quienes acusó de provocar la intervención de la masonería estadounidense y de poner en riesgo la soberanía nacional.

... el Consejo Sur de los Estados Unidos ..., para proteger (a) sus compatriotas, ... con el pretexto de la defensa de los principios masónicos, ..., justifi(ca) su intervención en ... este Alto Cuerpo obligándole, como ... pretende, á rescindir los tratados ... con las GGr[andes] LLog[ias] Nacionales y á reconocer como la única ..., á la Gran Dieta ... donde se esconden mañosamente bajo el mentido título de mexicanos, extranjeros cuyas miras ... son ... adueñarse de la Masonería Nacional,

\footnotetext{
${ }^{9}$ Boletín Masónico. Órgano Oficial de la Gran Dieta Simbólica de los Estados Unidos Mexicanos (México:

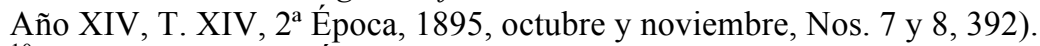

${ }^{10}$ Boletín Masónico. Órgano Oficial de la Gran Dieta (México: Año XIV, T. XIV, 2 a Época, 1895, octubre y noviembre, Nos. 7 y 8, 392-394); Boletín Masónico. Órgano Oficial de la Gran Dieta (México: Año XV, T. XV, 2a Época, 1896, noviembre, No. 11, 650-651). Richard E. Chism, Mexican Masonry (Mexico: Gante Press, 1893); Chism, Mexican Symbolic Masonry. The true and the false with special reference to the Grand Lodge of Free and Accepted Masons of the Federal District of Mexico (Mexico: Published by the Author, 1897); Chism, Free Masonry or Humbuggery. A tract for Toltec Lodge and other Lodges under the Gran Dieta of Mexico with a historical Chart of the Grand Lodge of the Federal District of Mexico (Mexico: Published by the Author, 1897); Chism, More Light upon Mexican Symbolic Masonry. A Circular to the Grand Lodges of Free Masons of the United States with a historical Chart of the Grand Lodge of the Federal District of Mexico (Mexico: Published by the Author, 1897); Chism, Una contribución a la Historia Masónica de México, 49.
} 
con fines siniestros respecto del porvenir de la Patria que tenemos el deber de conservar tal como nos la legaron libre, independiente y soberana, nuestros augustos predecesores.

La cuestión entre la Gran Dieta y el Supremo Consejo... es ... alarmante, ... trascendental, ... para la ... Patria. ... se discute, ... un hecho de vida ó de muerte de alguno de los dos rivales.

Si ... cediéramos á las amenazas del Supremo Consejo Sur, perderíamos ... nuestra autoridad jurisdiccional y ... nuestra independencia y soberanía masónicas, lo que ... prepararía la pérdida de nuestra independencia y soberanía nacionales. Eso no puede ser y ningún masón mexicano lo consentiría ${ }^{11}$.

El general tuvo razón. Para 1899 'Valle de México' y la Gran Dieta eran dominadas por extranjeros que acabaron con la Dieta el 30 de abril de $1901^{12}$. Sin la cohesión nacional que tuvo hasta 1901, para 1903 ya se decía que 'Valle de México' 1 era sostenida con el "elemento americano", "pretendiendo ser Yorkina" y extendió su jurisdicción a todo el país ${ }^{13}$.

\section{Coaliciones por el régimen}

Para 1903, masones oaxaqueños residentes en el Distrito Federal firmaron un manifiesto a favor de la reelección de Díaz, entre ellos Luis Pombo como vicepresidente de la mesa directiva y Benito Juárez Maza como segundo secretario ${ }^{14}$. Y nuevamente años después, tras las declaraciones de Porfirio Díaz a James Creelman, de nuevo se dividieron los masones entre los que buscaban la continuidad del régimen con algunos cambios y bajo diferentes fórmulas electorales y los que exigieron la revolución política y social, de éstos se tratará más adelante. Así, Benito Juárez Maza (rito mexicano), quien había participado

${ }^{11}$ El 11 de marzo el SUPREMO CONSEJO también suspendió a CARLOS D. CURTIS $18^{\circ}$ y a FÉLIX IGLESIAS $18^{\circ}$. Supremo Consejo del 33 y último grado del Rito Escocés Antiguo y Aceptado para la jurisdicción masónica de los Estados Unidos Mexicanos, Boletín Anual del Supremo Consejo del Rito Escocés Antiguo y Aceptado para los Estados Unidos Mexicanos (México: Tip. El Faro, Año $2^{\circ}$ del $8^{\circ}$ quinquenio, mayo de 1899 a abril de 1900), 20-21, 32, 35, 54-56; Supremo Consejo del 33 y último grado del Rito Escocés Antiguo y Aceptado para la jurisdicción masónica de los Estados Unidos Mexicanos, Translation from the Annual Report of the Supreme Council 33 of Mexico for 1900 (Mexico: Tip. Hamilton p Cía., 1900), 1-2, 7, 9.

${ }^{12}$ Recibió un disparo el día 6, murió el día 14. Gran Logia de Antiguos, Libres y Aceptados Masones Valle de México, Constitución Estatutos y demás Leyes de la Gran Logia de Antiguos, Libres y Aceptados Masones "Valle de México", Oficinas tipográficas de Federico M. Fusco, México, 1900, 71-73. Grand Lodge Valle de Mexico, Annual Communication of the Grand Lodge Valle de Mexico, A. F. and A. M. The City of Mexico, Jan. $4^{\text {th }}$ 1902, Tip. de F. M. Fusco, Mexico, 1902, 13, 16-17.

${ }^{13}$ La tolerancia. Órgano del Rito Nacional Mexicano, Publicación mensual, Casa Editorial de Eusebio Sánchez, Cuaderno N. 3, México, noviembre, 1903, Tercera de forros.

${ }^{14}$ Román Iglesias González (introducción y recopilación), Planes politicos, proclamas, manifiestos y otros documentos de la Independencia al México moderno, 1812-1940 (México: UNAM, IIJ, Serie C: Estudios Históricos, N. 74, 1998), 511-515. 
en el PARTIDO LIBERAL MEXICANO de la República en 1892, en 1903 firmó a favor de la reelección de Díaz y en enero de 1909 encabezó el PARTIDO DEMOCRÁTICO para postularlo de nuevo, y si bien decía condenar como un engaño el sufragio indirecto y pedía libertad efectiva y voto público, Juárez Maza era consistente con la postura que adoptó en 1902 al asumir el cargo de comendador del Rito Nacional Mexicano ${ }^{15}$, en aquella ocasión afirmó:

El Rito Nacional Mexicano hace público que comienza su vida actual con dos actos de justicia y de gratitud. Es el primero, el nombramiento de Gran Comendador ad vitam, en la ya prestigiada figura de nuestro actual Presidente de la República, Hermano Porfirio Díaz, masón del Rito Nacional Mexicano, como grado $9^{\circ}$ desde 1868. El que ha sabido mantener la paz, prestigia con un solo nombre un movimiento que tiene por objeto la identificación de ideales para sostener nuestra gran bandera: Constitución y Reforma ${ }^{16}$.

Por otra parte, el también masón escocés Rafael Zubarán Capmany había participado de la creación del partido y pocos meses después desde el CLUB SOBERANÍA POPULAR, que tenía entre sus dirigentes al escocés José López-Portillo y Rojas, postuló la fórmula Porfirio Díaz presidente-Bernardo Reyes vicepresidente, sin embargo, al declinar éste a ser candidato en alguna fórmula en julio de 1909, el partido no trascendió y Reyes debió salir a Europa en "comisión oficial", el grupo hacía proselitismo desde el periódico El Partido Democrático ${ }^{17}$.

También hubo masones en el CÍRCULO NACIONAL PORFIRISTA que postulaba la fórmula Porfirio Díaz-Teodoro A. Dehesa, ambos escoceses, su vicepresidente, José López Portillo y Rojas, pertenecía a la misma logia que Filomeno Mata y Joaquín Diego Casasús. Este último y el también masón José Castellot (grado $33^{\circ}$ desde julio 4, 1900) ${ }^{18}$, además formaron parte de la CONVENCIÓN REELECCIONISTA. En abril de 1909, el PARTIDO REELECCIONISTA del que eran parte los cientificos y masones Casasús, el banquero José Castellot y Emilio Rabasa, postuló la fórmula Porfirio Díaz-Ramón Corral, con el apoyo de los periódicos El Imparcial, El Reeleccionista y El Debate ${ }^{19}$.

\footnotetext{
${ }^{15}$ Iglesias González, Planes políticos, 521-528. La tolerancia, noviembre, 1903, 11.

${ }^{16}$ La tolerancia, noviembre, 1903, 12-13.

17 Iglesias González, Planes políticos, 554-561. Josefina Mac Gregor, "Intentos democratizadores: las campañas presidenciales de 1910 y 1911”, en Candidatos, campañas y elecciones presidenciales en México. De la República Restaurada al México de la alternancia: 1867-2006, coord. José Georgette (México: UNAM / IIS, 2012), 186.

${ }^{18}$ Supremo Consejo del 33 y último grado del Rito Escocés Antiguo y Aceptado para la jurisdicción masónica de los Estados Unidos Mexicanos, Boletín del Supremo Consejo del R[ito] E[scocés] A[ntiguo] y A[ceptado] para la jurisdicción de los EE[stados] UU[nidos] Mexicanos (México: Souligny \& Schmidt Sucr., 1927), 157.

${ }^{19}$ Iglesias González, Planes politicos, 529-535, 572-575. Mac Gregor, “Intentos democratizadores”, 186.
} 


\section{Coaliciones por la transición electoral y la revolución política}

Entre los que se oponían a la continuidad de Porfirio Díaz y querían la transición en las urnas estaba Filomeno Mata, quien desde su Diario del Hogar denunció que Díaz combatía el principio de la NO REELECCIÓN que defendió en el Plan de Tuxtepec años atrás y, desde abril de 1888 había impulsado la candidatura del masón José María Iglesias, quien en los grados superiores al $4^{\circ}$, también pertenecía al Supremo Consejo en el que estaban Porfirio Díaz y $\mathrm{Mata}^{20}$.

Otra corriente que también quería la alternancia fue la de El PARTIDO ANTIREELECCIONISTA NACIONAL en Yucatán, en 1909 presidido por el escocés José María Pino Suárez, además, ese partido en la ciudad de México tenía a los masones Francisco I. Madero como vicepresidente y como secretario a Mata. En la misma vertiente, era masón Juan Sánchez Azcona, quien dirigió el 3 de octubre de 1910 un manifiesto al PARTIDO ANTIRREELECCIONISTA y al PARTIDO DEMOCRÁTICO para anunciarles la disolución del comité ejecutivo electoral y, en conjunto, los masones escoceses Madero, Pino Suárez y Sánchez Azcona. crearían el Plan de San Luis Potosi ${ }^{21}$.

\section{¿Traición antiliberal?}

Otro grupo que postuló a Madero fue el PARTIDO CATÓLICO NACIONAL, con la fórmula Francisco I. Madero presidente-Francisco León de la Barra vicepresidente, con apoyo de los diarios nacionales El Tiempo y El País, en Guadalajara El Partido Católico, en Zamora Verdad y Justicia, en Morelia El Partido Nacional, en la Ciudad de México El Centro y El Cruzado, en Zacatecas El Demócrata, en Aguascalientes El Eco Social y su órgano oficial era La Nación ${ }^{22}$. Los católicos apoyaron al masón escocés Madero, porque, como dijo La Patria bajo el título: "Madero no puede ser Presidente de la República. No podría prestar la protesta de ley, porque ha ofrecido al Partido Católico que no se cumplirán las Leyes de Reforma. Así lo declara el Ilmo. señor Doctor Don José María Mora y del Río, Arzobispo de México"; el Arzobispo lo confirmó al declarar que: "El señor Don Francisco I. Madero no acotara (sic.) Las Leyes de Reforma, y á esto se debe que el Partido Católico le haya aceptado como su candidato á la Presidencia de la República"23.

\footnotetext{
${ }^{20}$ Diario del Hogar. Periódico de las familias, México, 1887, A. VII, N. 25, octubre 15, 1; N. 27, octubre 18; N. 28, octubre 19,$3 ; 1888$, N. 194, abril 29, 1-2.

21 Iglesias González, Planes políticos, 543-545, 562-565, 578-579. Manuel González Ramírez, Planes politicos y otros documentos, $1812-1940$ (México: Secretaría de la Reforma Agraria SRA / Centro de Estudios Históricos del Agrarismo en México CEHAM, 1981), 33-46. Francisco I. Madero, Plan de San Luis, facsímil del original mecanográfico, con correcciones de puño y letra de Francisco I. Madero, en el septuagésimo aniversario de su promulgación (México: Secretaría de Gobernación, 1980).

22 Mac Gregor, "Intentos democratizadores", 207.

${ }^{23}$ La Patria. Diario de México, México, 1911, T. XXXV, N. 9995, agosto 26, 2.
} 
Sobre el mismo tema, 'Un Palafoxiano' se dirigió al director de El Imparcial en defensa del PARTIDO CATÓLICO NACIONAL y acusó a El País, por olvidar la religión y ensalzar a Madero, a quien meses antes reprobó duramente: “Moralmente, 'El País' se ha convertido en órgano de la Masonería, puesto que es notorio que el señor Madero es un iniciado y asistió á la logia 'Lealtad' con aquel carácter. El señor Madero será en estos días ó es ya jefe de la Masonería de México. Ante estos hechos, yo, como católico, me pregunto: pues qué, ¿acaso los redactores de 'El País' estaban ya iniciados en las instituciones masónicas como los señores Garibaldi y Hay?"24 Sobre ese evento en la logia, El Imparcial había publicado dos días antes, el 22 de junio de 1911, lo siguiente:

\section{EL SR. MADERO EN LA LOGIA MASONICA 'LEALTAD'}

Se han Iniciado Algunos Jefes Revolucionarios

La Logia masónica 'Lealtad' celebró antenoche una sesión extraordinaria, habiendo sido especialmente invitado á ella el socio de grado catorce, señor D. Francisco I. Madero.

Se quiso dar el acto solemne severidad, y se consiguió, pues á las nueve de la noche, lo más granado de la institución llenaba la sala en que habría de celebrarse la tenida. Todos los concurrentes vestían de etiqueta, presidiendo la ceremonia los socios Grandes Comendadores, señores José Castellot y Lorenzo Spyer.

El señor Madero fue recibido por una comisión de grandes dignatarios de la 'Lealtad,' quienes lo condujeron, como una demostración de respeto y simpatía, á ocupar un sitio en el Gran Oriente, lugar que sólo ocupan los más altos dignatarios.

Varios masones hicieron uso de la palabra, y entre ellos, el señor Lic. Zayas, que recitó una composición poética, hija de gallarda musa.

Al terminar de hablar los hermanos, el señor Madero hizo uso de la palabra, felicitándose de pertenecer á la Institución, de la que dijo era uno de los más firmes apoyos sociales, variando luego de tema para hacer un detenido relato de la toma de Ciudad Juárez.

Terminado que hubo el 'leader' de la revolución, los caballeros Cadoch (sic.) y Rosa Cruz invitáronlo á una cena en el Salón Bach, á la que se excusó de asistir cortésmente.

Créese que con el ingreso del señor Madero, la 'Lealtad' tomará un grande impulso, pues sólo el rumor de que ya fueron iniciados los ex - revolucionarios Garibaldi, Hay y otros, ha causado grande animación en muchos que aspiran ser también iniciados" 25 .

En esa línea, Jesús Ceballos Dosamantes publicó en La Patria el 12 de agosto: El Neo-Ocultismo Jesuita. Una Plataforma que contiene la derogación de las leyes de

\footnotetext{
${ }^{24}$ El Imparcial. Diario Independiente, México, 1911, T. XXX, N. 6292, junio 24, 4.

${ }^{25}$ El Imparcial. Diario Independiente, México, 1911, T. XXX, N. 6290, junio 22, 5.
} 
Reforma y el aniquilamiento de la Escuela Laica ${ }^{26}$ y acusó a Madero de adherirse a un sistema masónico ocultista, mezcla de espiritismo, masonería y catolicismo, creado por el jesuita Joséphin Merodak Péladan, un delegado del Papado romano, que salió del Vaticano hacia Francia con un grupo encabezado por el Dr. Encause (Papus), para constituir la Rosa Cruz Católica, una rama ocultista subordinada al catolicismo y fiel al $\mathrm{Papa}^{27}$ (la ORDEN RUSACRUZ CATÓLICA Y ESTÉTICA DEL TEMPLO Y DEL GRIAL). Además denunció que en México una rama de una liga oculta anarquista internacional derivó en el CENTRO ESOTÉRICO DE MÉXICO o CENTRO ESOTÉRICO MEXICANO, creado en el Paseo de la Reforma en la ciudad de México por Alberto Santine Sgaluppi, alias 'Conde de Sarak o de Das', que se decía inspector general y visitador delegado de los grandes iniciados del Tibet, antes preso en Madrid y en Bruselas y expulsado de la SOCIEDAD TEOSÓFICA, quien fue defendido ante las acusaciones de Dosamantes por el masón y general José de la Paz Álvarez, miembro del CENTRO ESOTÉRICO (gran maestro entre 1883 y 1885 de la GRAN LOGIA DEL DISTRITO FEDERAL, la misma que dirigió Benito Juárez Maza entre 1889 y 1894). Dosamantes enfatizó que podían atentar contra el Estado usando a neuróticos sugestionados:

... tras ... neuróticos sugestionados que han perpetrado ... atentados políticos en ... Jefes de Estado ... están los ... sugestionadores, los Magos Negros: ya ... lleven la sotana del jesuita ya los títulos de pseudo-ocultista, cual sucede con un falso Doctor y Conde, que ha sido presidiario en las cárceles de España y de Bélgica ... Magos Negros ... que dirigen la Internacional Maffia (sic.) ...

Existen logias secretas en las cuales están ligados ... los que ... ante el mundo, serían elementos antagónicos; pero en sus solidarios fines de anarquía y de negación, se dan la mano los Magos Negros; ya ... en la Compañía de Loyola, ... en los centros del pseudo-ocultismo, ... entre ... cabalistas masones y en el pseudopositivismo, ora en los puestos públicos. Es la Compañía de Loyola el alma madre

\footnotetext{
${ }^{26}$ La Patria. Diario de México, México, 1911, T. XXXV, N. 9988, agosto 12, 1-2. Ceballos Dosamantes escribió obras con la pretensión de hacer una síntesis filosófica 'positiva' entre la ciencia y la religión, contra el materialismo, el catolicismo y el ocultismo, y contra lo que llamó la "mistificación maderista", Jesús Ceballos Dosamantes, El perfeccionamiento absoluto. Bases fundamentales de un nuevo sistema filosófico (México: Imprenta de Eduardo Dublán, 1888); Ceballos Dosamantes, Fariseos y Saduceos modernos. (Místicos y materialistas) (México: Tipografía de Dublán y Compañía, 1889); Ceballos Dosamantes, Ciencia y religión del porvenir. Solución a los grandes problemas (México: Eduardo Dublán Impresor, 1897); Ceballos Dosamantes, La gran mistificación maderista. Jesuitas y pseudo-científicos ante la moral y la ciencia (México: Imprenta de A. Carranza e Hijos, 1911). En su época fue refutado con mofa, también defendido en exceso por su discípulo Gonzalo Peña y Troncoso, El Dosamantismo es la Religión Científica en oposición al Ocultismo Semita, que es una Liga de Internacional Anarquismo. La Síntesis CientíficoReligiosa del maestro Jesús Ceballos Dosamantes (México: Editores J. I. Guerrero y Cía., Sucs. de F. Díaz de León, 1904). Véase: Emeterio Valverde Téllez (1864-1948), “Crítica filosófica o Estudio bibliográfico y crítico de las obras de Filosofía escritas, traducidas o publicadas en México desde el siglo XVI hasta nuestros días (1904), Capítulo XXV. El Perfeccionismo absoluto" [citado el 11 de noviembre de 2015]: disponible en http://www.filosofia.org/aut/001/ev190425.htm

${ }^{27}$ Peña y Troncoso, El Dosamantismo, $3^{\mathrm{a}}$. Parte, Capítulo VIII.
} 
en esta nefanda obra, y para congregar á todo el grupo tenebroso ha inventado la Política de Conciliación. ${ }^{28}$

Para Dosamantes, esas conexiones explicaban por qué Madero era "á la vez masón, espiritista y jesuita, que quiere derogar las Leyes de Reforma y aniquilar la Escuela Laica"; pues la libertad de enseñanza de su discurso del 18 de julio era para enseñar el catecismo jesuita de Ripalda en las escuelas públicas y en la enseñanza oficial ${ }^{29}$, como se hacía en las particulares; conforme a su promesa de anular las Leyes de Reforma. Por ello Dosamantes exigía al general Bernardo Reyes impedir que lo colocaran al lado de un "Vicepresidente clerical”, por grave y peligroso, "porque la Hidra Clerical, con un atentado político, dejaría al frente del Gobierno de la República á un Vicepresidente, que siendo de su devoción, daría un golpe de Estado." Así alertaba del peligro que atribuía a los intereses de los jesuitas, de los extranjeros y de la prensa comprada por éstos y por el clero, y sólo confiaba en el ejército.

Sí, si hay de quién esperar: de ese valiente y pundonoroso Ejército, que tiene jefes y oficiales cuya ilustración jamás les permitirá ser clericales; jamás tomarán ante la Historia Patria por modelo, al tigre traidor Leonardo Márquez y sí á un Leandro Valle, á un Ignacio Zaragoza; sí, mucho debemos esperar de ese Ejército, que en su última fiesta en honor del recto correctísimo Sr. Presidente Lic. Francisco L. de la Barra. tuvo cariñosas y entusiastas manifestaciones de adhesión para el Primer Magistrado de la República, que es digno hijo de uno de los jefes de la Reforma, é hizo extensivas sus entusiastas manifestaciones al Sr. Gral. D. Bernardo Reyes (grado $33^{\circ}$ desde diciembre 18, 1892) ${ }^{30}$. En cambio tuvo marcadísimos impulsos de protesta ante Madero, que con su sola presencia ante aquellos jefes y oficiales del Ejército de la República, constituía algo extraño. Si el respeto que el Sr. Presidente les merecía á aquellos militares, no los hubiera detenido, ellos hubieran dicho: $<<$ déjanos; aléjate con tú plataforma que es contraría á nuestras instituciones. $>>$ JESUS CEBALLOS DOSAMANTES ${ }^{\prime 31}$.

\footnotetext{
${ }_{28}^{28}$ Peña y Troncoso, El Dosamantismo, 2 ${ }^{\mathrm{a}}$. Parte, Cap. I, III; Cap. II, I, II; Cap. III, II.

${ }^{29}$ Jerónimo de Ripalda (S. J.), Catecismo y exposición breve de la Doctrina Cristiana. Nuevamente aumentado con cuatro tratados muy devotos, y el orden de ayudar a la Misa, con un Acto de contrición (Barcelona: Imprenta de Francisco Rosal, 1880).

${ }^{30}$ Supremo Consejo del 33 y último grado del Rito Escocés Antiguo y Aceptado para la jurisdicción masónica de los Estados Unidos Mexicanos, Boletín del Supremo Consejo del R[ito] E[scocés] A[ntiguo] y A[ceptado] para la jurisdicción de los EE[stados] UU[nidos] Mexicanos (México: Souligny \& Schmidt Sucr., 1927), 157.

${ }^{31}$ La Patria. Diario de México, México, 1911, T. XXXV, N. 9988, agosto 12, 2.
} 


\section{Revolución social Vs. Revolución política e intereses extranjeros}

Años atrás, en 1900, el mismo en el que los hermanos Ricardo, Enrique y Jesús Flores Magón fundaron el periódico Regeneración, Jesús recibió los grados $4^{\circ}$ al $14^{\circ}$ del Supremo Consejo en el que estaba Porfirio Díaz y El Diario del Hogar notificó que en el ceremonial fúnebre por la muerte del abogado Thomas Caswell gran comendador de la jurisdicción sur de los Estados Unidos, la oratoria la cerró Jesús Flores Magón ${ }^{32}$. Para 1911, Ricardo en Regeneración publicaba "El Judas Madero", y decía:

Mientras ls (sic.) valientes se baten, Madero y Díaz regatean como dos mercachifles el precio de la paz. Veinte millones de pesos pide Madero para rendir las armas, aparte de empleos y posiciones más o menos encumbradas para sus favoritos. En cuanto á los simples soldados maderistas, se les refundirá en los cuarteles de la Dictadura....

La traición de Madero es manifiesta: los generalillos maderistas y los soldados del llamado Ejército Libertador, que es el de Madero, están ya recibiendo paga de Díaz, así como proviciones (sic.). El General Navarro da las proviciones (sic.) para los hombres que están con Madero. ¡Veneno les había de dar ya que no saben ser dignos!

La Bandera Roja, entretanto, continúa la lucha. La Bandera Roja no admite componendas. Agrupáos, hermanos desheredados, alrededor de nuestra querida enseña que lleva inscriptas estas bellas palabras: ¡Tierra y Libertad! $!^{33}$

Además, Ricardo acusaba a Madero de sobornar a los "rebeldes liberales".

\section{MADERO SOBORNADOR}

Nuestros hermanos Lázaro S. Alanís é Inés Salazar, pudieron fugarse de las ergástulas maderistas. Están libres, y, como siempre, resueltos á luchar por la Bandera Roja.

El mentecato Madero supo que Alanís se encontraba en El Paso, y lo mandó llamar. Tres veces se negó Alanís á tener una entrevista con el burgués, hasta que por fin, fastidiado de la terquedad del payaso de la boleta electoral, y como valiente que es, pasó a ver á Madero.

... Madero le ofreció al camarada Alanís el oro y el moro, con tal que le ayudase. Madero dijo, además, á Alanís, que empleara toda su influencia para que los rebeldes liberales de la Baja California rindiesen las armas.

Alanís, naturalmente, despachó noramala al nuevo Judas. ${ }^{34}$

\footnotetext{
${ }^{32}$ Supremo Consejo del 33 y último grado del Rito Escocés Antiguo y Aceptado para la jurisdicción masónica de los Estados Unidos Mexicanos, Boletín Anual del Supremo Consejo del Rito Escocés Antiguo y Aceptado para los Estados Unidos Mexicanos (México: Tip. El Faro, Año $2^{\circ}$ del $8^{\circ}$ quinquenio, Mayo de 1899 a abril de 1900), 282. El Diario del Hogar, México, 1900, A. XX, N. 80, 18 diciembre, 2.

${ }^{33}$ Regeneración. Semanal revolucionario, Los Angeles, California, U. S. A., 1911, mayo 6, 2.
} 
Para los Flores Magón y el PARTIDO LIBERAL MEXICANO, la diferencia estaba en el programa. Mientras ellos decían buscar la revolución social y terminar con la propiedad privada, afirmaban que la revolución política de Madero implicaba sólo cambiar de "amos".

La de Madero es una revolución política porque no trata más que de un cambio de amos, quedando el proletariado en la misma condición en que se encuentra actualmente. Por el contrario la revolución que representa el Partido Liberal Mexicano, es una Revolución Social porque tiende á aniquilar el llamado derecho de propiedad con el fin de que todo lo que existe quede en poder de todos y cada uno de los habitantes de México... RICARDO FLORES MAGON ${ }^{35}$.

Asimismo, Ricardo denunció a los maderistas de asesinar liberales y obreros, a la verdadera obra revolucionaria, y llamaba "A unirse todos á las huestes liberales. ¡Muera Madero!” porque, dijo, había vendido México a la STANDARD OIL COMPANY, y el dinero para armar a sus hombres había salido "de las cajas del Rey del aceite, John D. Rockefeller”, y por esa razón perseguía a la casa PEARSON ${ }^{36}$, para él, estaba vendido a los americanos.

La mejor prueba de que Madero está vendido a los americanos, de que es un simple muñeco que se mueve al antojo de los capitalistas de esta nación, es el hecho de haber intrigado... por hacer que el poeta argentino Manuel Ugarte... se desistiera de dar una conferencia titulada 'Ellos y Nosotros,' en que el autor se propone hablar de las ambiciones de los Estados Unidos de hacer sus vasallos á todos los pueblos de la América Latina.

Madero, por medio del Ministro de Relaciones Exteriores, Manuel Calero, y éste, por medio de Justo Sierra... trataban de corromper á Ugarte, dándole dinero para que no hablase.

... La persecución de que somos objeto los revolucionarios en este país, es con lo que el Gobierno Americano paga á Madero, los favores y el apoyo que los aventureros americanos reciben en México ${ }^{37}$.

En el mismo sentido, el 26 de agosto de 1911 en El Tiempo se escribió que los yankees estuvieron detrás de todos los movimientos bélicos y divisiones entre mexicanos y que el general Porfirio Díaz había caído de la silla presidencial, "más que por la opinión pública, por la astucia, sagaz y pérfida intervención de los yanquis, motivada por el justo,

\footnotetext{
${ }^{34}$ Regeneración. Semanal revolucionario, Los Angeles, California, U. S. A., 1911, mayo 6, 2.

${ }^{35}$ Regeneración. Semanal revolucionario, Los Angeles, California, U. S. A., 1911, mayo 18, 2.

${ }^{36}$ Regeneración. Semanal revolucionario, Los Angeles, California, U. S. A., 1911, junio 3, 1; junio 10, 2; septiembre 16, 3 .

${ }^{37}$ Regeneración Semanal revolucionario. Escrito por trabajadores y para los trabajadores, Los Angeles, California, U. S. A., 1912, febrero 3, 1.
} 
debido y necesarisimo apoyo ó alianza que solicitó, ya tarde, y la cual todo buen gobierno mexicano debe solicitar contra estos primos, el de otra potencia terrible para ellos, es decir la del Japón." Y fue sostenida como hipótesis que los yankees escogerían a Madero, a Reyes y...

Si ninguno de éstos lo fuese, entonces, con su característica astucia, incitarán otra nueva revolución para derribarle y provocar más o menos tarde su descarada y descubierta intervención, con el pretexto de proteger á sus súbditos y á sus intereses. Será el cumplimiento de los deseos de nuestros jurados enemigos.

Estas son verdades palmarias: por tanto, en vano se formarán clubs y se proclamará en todos los tonos libertad de sufragio; no ocupará la Presidencia sino aquél que los americanos quieran y consientan." Por ello llamaba a la unión de todos los partidos y clubs para elegir un Presidente civil o militar anti-yankee. VALENTIN DUOAN DE PEREDA ${ }^{38}$.

Otros dijeron que se opuso a Estados Unidos por el problema de EL CHAMISAL. Del 15 de mayo al 2 de junio de 1911, se reunió una Comisión o Tribunal de Arbitraje (instalado en la ciudad de El Paso) y celebró 13 sesiones dedicadas a los alegatos orales y ocho a la discusión de las pruebas. Los agentes representantes de cada uno de los países en disputa fueron Joaquín D. Casasús por México y William C. Dennis por Estados Unidos. El primer gobierno en ocuparse del problema de EL CHAMISAL fue el del presidente Madero, desde su primer informe al Congreso de la Unión le dedicó la primera parte de su discurso y manifestó que el gobierno mexicano consideraba el arbitraje un éxito y comunicó al gobierno de Estados Unidos que: “...sin prescindir de la posición que le ha dado el fallo arbitral, escuchará y estudiará las proposiciones que el gobierno americano tenga a bien hacerle" 22 .

\section{Coalición y traición por la presidencia}

Sobre el general Bernardo Reyes, desde 1905 los Flores Magón publicaron “¡ALERTA, MASONES!”, para prevenir que estaban formándose logias para elevar a la Presidencia de la República a "ese tirano" y acompañaron la nota de una carta de "Un Masón” que resulta interesante reproducir porque muestra la división interna en la masonería.

Chihuahua, Septiembre de 1905

Sres. R. R. de REGENERACION.

St. Louis, Mo.

${ }^{38}$ El Tiempo. Diario Católico, México, 1911, A. XXIX, N. 9246, agosto 12, 5. 
Muy señores mios:

La masonería en México está siendo desprestigiada por sus Jefes. Las conveniencias políticas de los serviles grados 33 que componen el Supremo Consejo del Rito Escocés Antiguo y Aceptado, de México, han engendrado el cisma y la decepción. Por esa circunstancia muchos masones honrados se han retirado, eludiendo el contacto con los policastros defensores de un Comendador 'ad vitam' (Porfirio Díaz) que ha asesinado á tantos y muy notables hermanos, y han formado un grupo masónico que, si no es reconocido como regular, es en la práctica mas regular que la masonería del Supremo Consejo, puesto que no sacrifica los principios á las torpes conveniencias personales.

Es verdad que en el grupo de los masones honrados hay obreros y no generales ni diputados como en el Supremo Consejo; pero también es verdad que esa gente de trabajo es más digna de respeto por su honradez, su buena fe, su patriotismo y sus tendencias liberales, que las hipócritas patrioterías de Rafael Nájera, que las dobleces masónico católicas de Paz Alvarez, que las estafas y peculados inteligentes del ex-Cónsul Rafael Zayas Enríquez, que los burdos chantages (sic.) de Castillo Velasco, que las falsedades de Miguel Ahumada, que las herencias a fortiori de Domingo León, y las mil y una bribonadas de tanto grado 33 entre los que descuella el famoso Bernardo Reyes que nunca ha sido masón, ni puede tampoco serlo, desde el momento que ha manchado sus manos con la sangre del pueblo.

La masonería es la institución más noble que existe sobre la haz (sic.) de la tierra, puesto que tiene por programa el mejoramiento moral y material de la humanidad, y por lo tanto no puede ser asilo de los pillos, de los asesinos y de los ladrones. Es, pues, inconcebible que Bernardo Reyes tenga el grado 33 y facultades para que él y sus Agentes den grados á diestra y siniestra y al primero que pague, y sin embargo, así es para mayor vergüenza y desprestigio de ese Supremo Consejo que por perjudicial debería ya haber desaparecido.

Para adular á su amo, el hipócrita Rafael Nájera, actual Oficial $1^{\circ}$ de la Secretaría del Congreso de Nuevo León, dirige la cuestión masónica en la Frontera, de acuerdo con el general reyista Jesús Alonso Flores, de México, y por esa causa hay agentes masónicos en le (sic.) frontera del Norte que reparten grados según la paga, sin fijarse en fórmulas ni nada. Lo que falta es que haya un Kadochk (sic.) que saque el puñal para defender la candidatura de su jefe, el epiléptico grado 33 Bernardo Reyes, cuando quiera ser Presidente de la República.

Deben, pues, cuidarse los masones de esta frontera para no caer en las garras de esos estafadores de dinero á pretexto de dar grados para después obligarlos á trabajar por el encumbramiento del asesino Bernardo Reyes.

¡Alerta, Masones!

Soy de U[ste]d[e]s. muy at[en]to. y S[eguro]. S[ervidor].- Un masón"39.

\footnotetext{
${ }^{39}$ Regeneración Periódico Independiente de combate. Saint Louis, Mo., E. U. A., 1905, septiembre 16, 2.
} 
También en 1905, en carta dirigida a Antonio Balboa de la hacienda del Parral Chihuahua, Ricardo Flores Magón le decía que en Monterrey, si bien había triunfos de la masonería, en sus logias había serios elementos de oposición que podían utilizar para combatir a Bernardo Reyes, que Balboa conocía a esos masones dignos, no sometidos a Reyes, y les prestaría un gran servicio, si recogía información de "los trabajos políticos de mala ley" de Reyes, "abusando de su grado masónico", así podrían impedir que sus "correligionarios afiliados al masonismo fueran engañados y comprometidos por las intrigas de Reyes", para ello le suplicó le informara ${ }^{40}$.

Lo mismo se decía en otra carta de 1907, que habría que cuidarse de ciertos masones "lacayuelos de Canana [Bernardo Reyes]"41 y, en el mismo año, Aarón López Manzano hizo ver a Ricardo Flores Magón que entre sus correligionarios había muchos masones, motivo por el que le preguntaba: "¿no cree usted que por ese medio se viera [Bernardo] Reyes entre nosotros?". Además le dijo que varios le habían preguntado si él, Ricardo, era masón, y que por política les había dicho que creía que sí, no obstante que mucho desconfiaba. ${ }^{42}$ Como prueba de que había masones a su favor, reproduzco la anécdota que Tomás Sarabia Labrada contó a Ricardo Flores Magón:

Adjunto a usted una carta de Juan [Sarabia], que me entregó ayer tarde el señor [Ignacio] Mendiola. Ha sido una gran casualidad el que obrara en mi poder. En carta anterior había yo dado a Juan para que me escribiera al nombre de la esposa de Mendiola que lo es Frances M. Braden, el anterior sobre, donde venían las cartas que mandé a usted traía la dirección bien correcta y puesta por puño de Juan, pero ahora, esta vez y según me dice Mendiola, el sobre sólo decía Mrs. Frances y en vez de traer dirección de 311 South, Santa Rosa Avenue fue a dar la carta al mismo número y calle, pero a distinto rumbo, es decir fue al norte, por fortuna en esa casa vive uno de los hermanos de Logia de Mendiola, ya la iban a poner al fuego sin abrirla, se les ocurrió abrirla, miraron signos y como en la masonería también usan ciertas claves, la entregaron a Mendiola, para ver si era de él, así es como vino a dar a mis manos, de lo contrario se hubieran perdido los interesantes datos que da. No creo que la persona que le servía de conducto le haya retenido sus cartas, pues yo no le contesté luego, es decir, no le contesté la última que de él mandé a usted, así es

\footnotetext{
${ }^{40}$ Ricardo Flores Magón, "Carta a Antonio Balboa de la Hacienda del Parral Chihuahua”, Saint Louis, Missouri, 14 de agosto de 1905 [citado el 15 de noviembre de 2015]: disponible en http://archivomagon.net/obras-completas/correspondencia-1899-1922/c-1905/cor56/

${ }^{41}$ Flores Magón, "Carta a Aarón López Manzano", [s.1.], 1 de abril de 1907[citado el 15 de noviembre de 2015]: disponible en http://archivomagon.net/obras-completas/correspondencia-1899-1922/c-1907/cor148/

42 A[arón] López Manzano, “Carta a Ricardo Flores Magón”, [s.1.], 21 de marzo de 1907[citado el 15 de noviembre de 2015]: disponible en http://archivomagon.net/obras-completas/correspondencia-1899-1922/c$\underline{1907 / \text { cor143/ }}$
} 
que mal puede esa persona haberle detenido sus cartas, siendo que nada ha recibido, a no ser que usted le haya escrito. Tomás Sarabia Labrada. ${ }^{43}$

Por supuesto, para 1911, Ricardo Flores Magón volvió a denunciar a Bernardo Reyes como un "personaje siniestro" y "sanguinario cosaco de Porfirio Díaz" que se preparaba para el cuartelazo, que había llegado a ser gobernador de Nuevo León "dejando tras de él un reguero de sangre y de lágrimas" por ser "un degenerado que siente placer matando"44.

\section{La renuncia de Díaz y la vía armada}

El 25 de abril de 1911, en la Gran Logia Valle de México se analizó la propuesta de Alberto Rodríguez Aréchiga, Juan Marmolejo y Alfonso F. Montenegro y Mata, miembros de la comisión nombrada para el establecimiento de la paz en la república. El proyecto proponía escribir a Porfirio Díaz y a Francisco I. Madero recordándoles su deber y “el juramento Masónico que prestaron de que no existan guerras intestinas en la Nación lo que está condenado por los principios Masónicos que conocen". Para ello facultaron a su gran maestro para que hiciera llegar las resoluciones lo más pronto posible. Montenegro firmó inconforme, para él la masonería en ese momento estaba rebasada y no tenía elementos para hacer admitir sus disposiciones; finalmente, el dictamen reformado quedó dividido en dos artículos, el primero fue aprobado por mayoría de 21 votos contra $5^{45}$.

Sobre el segundo artículo, el gran maestro no aceptó hacerse responsable. Montenegro lo apoyó, "indicando que estos eran trabajos de verdadera política y que pugnaban con los principios masónicos." Manuel R. García propuso que para redactar el texto, el gran maestro se asociara con el diputado gran maestro y los vigilantes. De los Ríos manifestó que "el punto a discusión nada tenía nada de político", que "estaba comprendido dentro de las enseñanzas del tercer grado" y preguntó a Montenegro si el respeto a la ley era antimasónico, a lo que contestó "Si se ha jurado por la Constitución ó por honor no se debe hacer política." La discusión se prolongó de manera agria por lo que el gran maestro la suspendió y la reanudaron el 3 de mayo. Ese día Eusebio Sánchez (en 1904 apareció en el cuadro electoral del Rito Nacional Mexicano como teniente gran comendador) ${ }^{46}$ externó que perdían el tiempo con la discusión y que el acuerdo sería extemporáneo por lo

\footnotetext{
43 Tomás Sarabia Labrada, "Carta a [Ricardo Flores] Magón [Los Ángeles, California]”, [San Antonio, Texas], 25 de julio de 1907[citado el 15 de noviembre de 2015]: disponible en http://archivomagon.net/obrascompletas/correspondencia-1899-1922/c-1907/cor249/

${ }^{44}$ Regeneración. Semanal revolucionario. Los Angeles, California, U. S. A., 1911, agosto 5, 2.

${ }^{45}$ A FAVOR: Aréchiga, Marmolejo, Urquiza, Zardo, J. M. Velasco, Gómez García, Gibert, De los Ríos, Rojas, Carlos García, Velo, Malagón, Mata, Arenas, León, De Luca, Pró, Huelgas, Sánchez y Muñoz. EN CONTRA: Melendez, Montenegro, Cos, Manuel Velasco y M. R. García.

${ }^{46}$ La tolerancia, Cuaderno N. 3, México, noviembre, 36.
} 
avanzados que estaban los "trabajos por la Paz, en el orden profano", no obstante, se programó votar al día siguiente la propuesta, y el gran maestro anunció que se abstendría de ejercer su derecho de firmar el texto.

Parece que el gran maestro siguió con su postura evasiva porque el 4 de mayo se ausentó, se dijo que por un accidente de su familia; fueron leídos los documentos que enviarían a Porfirio Díaz y a Francisco I. Madero, a los que llamarían muy queridos y venerables hermanos. Marmolejo propuso que el texto de Madero lo entregara Montuori, quien ya había cumplido una comisión semejante de la logia Lealtad, y que lo hiciera de inmediato porque Madero estaba muy retirado del centro y era "necesario valerse de todos los medios para que... llegara con toda oportunidad.", otros propusieron enviar copias a las grandes logias, logias y al supremo consejo; Huelgas y Campos manifestó que el último grupo no inspiraba confianza, lo que le reprendieron y tuvo que disculparse, su postura explicita las divisiones entre masones.

El 28 de mayo, Montuori informó que cumplió el encargo y fue leída la nota que "el V[enerable] H[ermano] Madero" envió a la gran logia ${ }^{47}$ y que podemos conocer porque fue publicada por Alberto Pro secretario de la gran logia (grado $33^{\circ}$ desde el 21 de abril de $1909^{48}$ ), el 30 de mayo en El Diario del Hogar:

Gran Logia de Libres y Aceptados Masones 'Valle de México'

SECRETARIA

Masones 'Valle de México' con fecha 4 del actual y que se sirvió Ud. publicar oportunamente en su apreciable periódico México, Mayo 29 de 1911.

Sr. Director del 'Diario del Hogar'

Muy Señor mío:

Tengo el gusto de insertar á Ud. la contestación á la comunicación que le dirigió esta Gran Logia de Antiguos Libres y Aceptados:

'Un sello que dice: $<<$ Gobierno Provisional de la República Mexicana.Secretaría de la Presidencia.- A la muy Respetable Gran Logia 'Valle de México', México, D[istrito] F[ederal].- En contestación de la atenta comunicación que de esa Muy Respetable Gran Logia he recibido, tengo el honor de manifestar á dicho Alto Cuerpo, que en caso de llegarse á celebrar algún arreglo con el Gobierno del General Díaz, para provecho de la Nación, tendré en cuenta las observaciones que se sirve hacerme esa M[uy] R[espetable] G[ran] L[ogia] y las aprovecharé en cuanto sea conveniente para el logro y la garantía de los principios políticos y sociales que dieron origen á la Revolución y que es absolutamente preciso que queden garantizados en definitiva, pues de otra suerte habríamos defraudado la sangre popular, tan generosamente vertida por la conquista de nuestras libertades.- Me es

\footnotetext{
${ }^{47}$ Gran Logia de Antiguos, Libres y Aceptados Masones Valle de México, libro de actas, México, 1911.

${ }^{48}$ Supremo Consejo del 33 y último grado del Rito Escocés Antiguo y Aceptado para la jurisdicción masónica de los Estados Unidos Mexicanos, Boletín del Supremo Consejo del R[ito] E[scocés] A[ntiguo] y A[ceptado] para la jurisdicción de los EE[stados] UU[nidos] Mexicanos (México: Souligny \& Schmidt Sucr., 1927), 157.
} 
grato hacer presente á esa M[uy] R[espetable] G[ran] L[ogia] los sentimientos de mi muy atenta consideración y fraternal concordia - En C[iudad] Juárez, á 16 de Mayo de 1911.- Francisco I. Madero, Rúbrica.'

Con este motivo me es grato repetirme su atto. S. S. ALBERTO PRO״49.

A finales de junio de 1911, la Gran Logia 'Valle de México' realizó la ceremonia del solsticio de verano para "celebrar la restauración de la paz en la República Mexicana”, en la Academia Metropolitana ${ }^{50}$. Sin embargo, el conflicto armado continuaría, aunque ya no contra Porfirio Díaz, sino entre los que se disputaron el poder cuando él se retiró, porque es probable que en atención a la petición masónica se haya firmado los Tratados de Ciudad Juárez por lo que Porfirio Díaz se comprometió a dejar la presidencia, él y Madero cesarían las hostilidades el 21 de mayo de 1911 y sólo 5 días después, el día 26, Díaz partió para Veracruz escoltado por el coronel Joaquín Chicharro y el general escocés Victoriano Huerta (que como podrá intuirse, después estaría envuelto en nuevas coaliciones y traiciones masónicas en la Decena Trágica de 1913). Además, como advertía Dosamantes, Francisco León de la Barra asumió la presidencia de la república, aunque de forma interina; y el ministro de gobernación Emilio Vázquez Gómez renunció y acusó a Madero de conservador y de proteger al antiguo régimen. Nuevamente 5 días después, el 31 de mayo Díaz salió rumbo a Europa y el siguiente mes Bernardo Reyes llegó a Veracruz el 4 de junio $^{51}$.

A nombre de la masonería el 3 de julio de 1911 el Supremo Consejo de México y la logia Progreso y Libertad 2, lamentaron la muerte del S[ublime] P[ríncipe] D[el] R[eal] S[ecreto] Filomeno Mata (masón grado $32^{\circ}$ ), y convocó a su sepelio ${ }^{52}$; y desde el Diario del Hogar que él fundó, el 10 de agosto con el título: ¿Será desafiado el 'leader' de la revolución? Un capitancillo en campaña. En estos momentos se discute si hay lugar al desafio, se mencionó que "Antes de anoche, en una logia", un "capitancillo retirado que quiere adquirir fama de notoriedad", manifestó que sería pertinente lanzar un cartel de desafío al "leader de la Revolución”, Francisco I. Madero, "por las palabras vertidas en la fiesta que el Ejército dió el domingo en Chapultepec". Los de esa logia en su mayor parte eran militares retirados y pretendían hacerle propaganda a Reyes, para acabar con el rival "que indudablemente se llevará la victoria". Uno le dijo al capitán que sólo quería notoriedad porque el duelo estaba prohibido en México y Madero no se batiría porque o no lo dejarían sus partidarios o uno de ellos saldría al frente, prometían al lector continuar

\footnotetext{
${ }^{49}$ Diario del Hogar, México, 1911, A. XXX-N. 10743, T. 47, N. 94, mayo 30, 4.

${ }^{50}$ Diario del Hogar, México, 1911, A. XXX-N. 10772, T. 47, N. 123, junio 28, 1.

${ }^{51}$ Chantal López y Omar Cortés (recopilación), Madero y los Partidos Antirreeleccionista y Constitucional Progresista (México: Ediciones Antorcha, 1988), 94-95, 122-133, 227-231. Pablo Serrano Álvarez, Porfirio Díaz y el Porfiriato. Cronología (1830-1915) (México: INERHM, 2012).

${ }^{52}$ Diario del Hogar, México, 1911, A. XXX-N. 10778, T. 47, N. 128, julio 4, 1.
} 
informando ${ }^{53}$. Sabemos nosotros que lo que siguió fue la reyerta armada y un proceso histórico que concluiría una década después.

\section{Conclusiones}

Analizar las divergencias políticas durante el gobierno de Porfirio Díaz permite advertir que tuvieron un sustento en coaliciones y traiciones masónicas, desde su primera reelección en 1887 hasta su salida del país en 1911 en los inicios de la revolución mexicana. De igual forma, quedó demostrado que hubo masones que apoyaron a Porfirio Díaz, otros que lo combatieron para buscar la transición electoral o la revolución política, liberal, social por medios violentos o que buscaron la paz, e incluso los que pactaron con el clero católico para derogar las Leyes de Reforma de la época juarista, y los que trabajaron por redimir al pueblo o los que favorecieron o pugnaron contra la intervención extranjera.

Aparte, pudo revisarse la visión que la historiografía masónica ha tenido por más de 100 años acerca de la Gran Dieta Simbólica, a la que se ha acusado de ser la causa de los grandes males de la masonería en México de finales del siglo XIX, sin considerar que a ella se debió la estabilidad del país, en una época en la que las divisiones masónicas podían provocar disputas armadas, debido principalmente a que varios dirigentes de las grandes logias eran a su vez gobernadores de estado y miembros destacados del ejército. Además, la Dieta permitió unificar dos vertientes escocesas, la del Supremo Consejo de México que buscaba la gobernabilidad del país y la del Gran Oriente que quería la democratización de la masonería y la secularización y educación de la sociedad. La Dieta permitió que ambos proyectos se consolidaran entre 1893 y 1895, cuando no sólo unió a los gobernadores escoceses bajo un solo proyecto, sino que incluyó a la mujer y en algunos casos prescindió del uso de la biblia en sus rituales.

No obstante, quedó claro que, desde el extranjero, bajo la excusa de la defensa de la masonería regular, infiltraron las logias, las obediencias y el Supremo Consejo, y que lograron incluso que el presidente de la república Porfirio Díaz renunciara a la Dieta y perdiera su cohesión, y finalmente la extinguieron en 1901. Lo que es significativo, porque de ese año y hasta 1911 varios indicios apuntan a que la caída de Díaz y la llegada de Madero, estaría incitada desde fuera del país por disputas comerciales internacionales.

Por supuesto, el análisis sugiere preguntas que dejaremos sin respuesta, aun así, con el breve recuento de las diferentes posturas políticas que adoptaron los masones, lo que resulta evidente, es que sus coaliciones y traiciones definieron el destino del país.

\footnotetext{
${ }^{53}$ Diario del Hogar, México, 1911, A. XXX-N. 10815, T. 47, N. 166, agosto 10, 2.
} 


\section{Archivos}

Archivo Electrónico Ricardo Flores Magón.

Archivo General de la Nación.

Benson Latin American Collection. University of Texas at Austin Libraries Biblioteca Nacional de México.

Biblioteca Nacional de México.

Grand Lodge of Pennsylvania.

Gran Logia Valle de México.

Grand Orient de France.

Hemeroteca Nacional de México.

Hemeroteca Nacional Digital de México.

Library and Museum of Freemasonry, United Grand Lodge of England.

Supremo Consejo de México.

The House of the Temple, Scottish Rite of Freemasonry Supreme Council, $33^{\circ}$ Southern Jurisdiction, Washington, D. C.

Universidad Autónoma de Nuevo León.

\section{Fuentes primarias}

\section{Hemerográficas}

Convención Radical Obrera. Órgano de la Sociedad del mismo nombre y de las clases obreras de toda la República, La. México.

Diario del Hogar. México.

Diario del Hogar

El Diario del Hogar

Diario del Hogar. Periódico de las familias

Imparcial. Diario Independiente, El. México.

Patria. Diario de México, La. México.

Regeneración. U. S. A.

Regeneración. Periódico Independiente de combate. Saint Louis, Mo., E. U. A.

Regeneración. Semanal revolucionario. Los Angeles, California, U. S. A.

Regeneración. Semanal revolucionario. Escrito por trabajadores y para los trabajadores.

Los Angeles, California, U. S. A.

Siglo Diez y Nueve. Decano de la Prensa Mexicana, El. México.

Tiempo, El. Diario Católico. México. 


\section{Manuscritos, documentos y correspondencia}

Flores Magón, Ricardo. "Carta a Antonio Balboa de la Hacienda del Parral Chihuahua". Saint Louis, Missouri, 14 de agosto de 1905. Disponible en http://archivomagon.net/obras-completas/correspondencia-1899-1922/c-1905/cor56/

Flores Magón, Ricardo. “Carta a Aarón López Manzano”. [s.1.], 1 de abril de 1907. Disponible en http://archivomagon.net/obras-completas/correspondencia-18991922/c-1907/cor148/

Gran Logia de Antiguos, Libres y Aceptados Masones Valle de México, libro de actas, México, 1911.

López Manzano, A[arón]. "Carta a Ricardo Flores Magón”. [s.1.], 21 de marzo de 1907. Disponible en http://archivomagon.net/obras-completas/correspondencia-18991922/c-1907/cor143/

Madero, Francisco I. Plan de San Luis, facsímil del original mecanográfico, con correcciones de puño y letra de Francisco I. Madero, en el septuagésimo aniversario de su promulgación. México: Secretaría de Gobernación, 1980.

Pombo, Ignacio, Balaustre 35, Tercera Serie, México, 25 del $3^{\text {er }}$ mes masónico Kislev de 5650, enero 2, 1890.

Pombo, Ignacio, Carta a Alberto Pike en Washington D. C. México, febrero 13, 1890.

Sarabia Labrada, Tomás. "Carta a [Ricardo Flores] Magón [Los Ángeles, California]”. [San Antonio, Texas], 25 de julio de 1907. Disponible en http://archivomagon.net/obrascompletas/correspondencia-1899-1922/c-1907/cor249/

\section{Publicaciones masónicas}

Boletín Masónico, El. Órgano Oficial del Supremo Gran Oriente de los Estados Unidos Mexicanos, Revista de la Masonería Universal. México.

Boletín Masónico. Órgano Oficial de la Gran Dieta Simbólica de los Estados Unidos Mexicanos. México.

Boletín Anual del Supremo Consejo del Rito Escocés Antiguo y Aceptado para los Estados Unidos Mexicanos. México.

Gran Logia de Antiguos, Libres y Aceptados Masones Valle de México. Constitución Estatutos y demás Leyes de la Gran Logia de Antiguos, Libres y Aceptados Masones "Valle de México". Oficinas tipográficas de Federico M. Fusco, México, 1900.

Grand Lodge Valle de Mexico. Annual Communication of the Grand Lodge Valle de Mexico, A. F. and A. M. The City of Mexico, Jan. $4^{\text {th }}$ 1902. Tip. de F. M. Fusco, Mexico, 1902.

Supremo Consejo del 33 y último grado del Rito Escocés Antiguo y Aceptado para la jurisdicción masónica de los Estados Unidos Mexicanos. Translation from the 
Annual Report of the Supreme Council $33^{\circ}$ of Mexico for 1900. Mexico: Tip. Hamilton p Cía., 1900.

Tolerancia. Órgano del Rito Nacional Mexicano, La. México.

\section{Bibliografía}

Berriozabal, Felipe B. Memoria que el Secretario de Estado y del Despacho de Guerra y Marina Gral. De División Felipe B. Berriozabal presenta al Congreso de la Unión y comprende de 19 de marzo de 1896 a 30 de junio de 1899. México: Imprenta 'Central', Anexos, Tomo II, 1900.

Ceballos Dosamantes, Jesús. El perfeccionamiento absoluto. Bases fundamentales de un nuevo sistema filosófico. México: Imprenta de Eduardo Dublán, 1888.

Ceballos Dosamantes, Jesús. Fariseos y Saduceos modernos. (Místicos y materialistas). México: Tipografía de Dublán y Compañía, 1889.

Ceballos Dosamantes, Jesús. Ciencia y religión del porvenir. Solución a los grandes problemas. México: Eduardo Dublán Impresor, 1897.

Ceballos Dosamantes, Jesús. La gran mistificación maderista. Jesuitas y pseudo-científicos ante la moral y la ciencia. México: Imprenta de A. Carranza e Hijos, 1911.

Chism, Richard E. Mexican Masonry. Mexico: Gante Press, 1893.

Chism, Richard E. Mexican Symbolic Masonry. The true and the false with special reference to the Grand Lodge of Free and Accepted Masons of the Federal District of Mexico. Mexico: Published by the Author, 1897.

Chism, Richard E. Free Masonry or Humbuggery. A tract for Toltec Lodge and other Lodges under the Gran Dieta of Mexico with a historical Chart of the Grand Lodge of the Federal District of Mexico. Mexico: Published by the Author, 1897.

Chism, Richard E. More Light upon Mexican Symbolic Masonry. A Circular to the Grand Lodges of Free Masons of the United States with a historical Chart of the Grand Lodge of the Federal District of Mexico. Mexico: Published by the Author, 1897.

Chism, Richard E. Una contribución a la Historia Masónica de México. México: Imp. de El Minero Mexicano, 1899.

Ferrer Benimeli, José Antonio. La Masonería Española en el Siglo XVIII. Madrid: Siglo XXI Editores, Historia, segunda edición corregida, 1986.

Freke Gould, Robert. Freemasonry in Mexico. U. S. A.: Kessinger Publishing, reprinted from Keble's Gazette Office, 1893 and from Ars Quatuor Coronati, London, reprinted by Kessinger Publishing, s.a.

González Ramírez, Manuel. Planes políticos y otros documentos, 1812-1940. México: Secretaría de la Reforma Agraria SRA / Centro de Estudios Históricos del Agrarismo en México CEHAM, 1981. 
Iglesias González, Román (introducción y recopilación). Planes políticos, proclamas, manifiestos y otros documentos de la Independencia al México moderno, 1812 1940. México: UNAM, IIJ, Serie C: Estudios Históricos, N. 74, 1998.

López, Chantal y Cortés, Omar (recopilación). Madero y los Partidos Antirreeleccionista y Constitucional Progresista. México: Ediciones Antorcha, 1988.

Mac Gregor, Josefina. "Intentos democratizadores: las campañas presidenciales de 1910 y 1911”. En Candidatos, campañas y elecciones presidenciales en México. De la República Restaurada al México de la alternancia: 1867-2006. Coordinado por José Georgette (México: UNAM / IIS, 2012), 181-219.

Martínez Moreno, Carlos Francisco. “Auge y Caída de la Masonería en México en el Siglo XIX. La Exclusión de la Mujer bajo la mirada del Discurso Masónico de Laureana Wright González". REHMLAC 4, no. 2, (diciembre 2012-abril 2013): 129-155. Disponible en http://revistas.ucr.ac.cr/index.php/rehmlac/article/view/12188/11471

Martínez Moreno, Carlos Francisco. "Masonerías y construcción de una geopolítica nacional”. En Escenarios geopolíticos para el México global. Un acercamiento a los temas del siglo XXI. Coordinado por Arturo Ponce Urquiza. México: Centro de Estudios Superiores Navales CESNAV/Grupo Editorial Cenzontle, 2015.

Parvin, Theodore Sutton. Mexican Masonry. Iowa: Cedar Rapids, May 17 th 1897.

Peña y Troncoso, Gonzalo. El Dosamantismo es la Religión Científica en oposición al Ocultismo Semita, que es una Liga de Internacional Anarquismo. La Síntesis Científico-Religiosa del maestro Jesús Ceballos Dosamantes. México: Editores J. I. Guerrero y Cía., Sucs. de F. Díaz de León, 1904.

Ripalda, Jerónimo de (S. J.). Catecismo y exposición breve de la Doctrina Cristiana. Nuevamente aumentado con cuatro tratados muy devotos, y el orden de ayudar a la Misa, con un Acto de contrición. Barcelona: Imprenta de Francisco Rosal, 1880.

Serrano Álvarez, Pablo. Porfirio Díaz y el Porfiriato. Cronología (1830-1915). México: INERHM, 2012.

Valverde Téllez, Emeterio (1864-1948). "Crítica filosófica o Estudio bibliográfico y crítico de las obras de Filosofía escritas, traducidas o publicadas en México desde el siglo XVI hasta nuestros días (1904), Capítulo XXV. El Perfeccionismo absoluto”. Disponible en http://www.filosofia.org/aut/001/ev190425.htm 